\title{
Physician-Patient Colorectal Cancer Screening Discussions by Physicians' Screening Rates
}

\author{
Cathleen M. O'Farrell, MD, MPH, Beverly B. Green, MD, MPH, \\ Robert J. Reid, MD, PhD, Deborah Bowen, PhD, and Laura-Mae Baldwin, MD, MPH
}

Background: Most physicians report routinely recommending colorectal cancer (CRC) screening, but many eligible patients are not screened. To better understand this finding, we explored the relationship between the content of hypothetical patient-physician CRC screening discussions and CRC screening rates in physicians' practices.

Methods: Semistructured interviews, including role-playing, with 24 primary care physicians explored their CRC screening approach with average-risk patients. Qualitative analysis examined physician-reported components of the CRC screening discussion, then compared findings between physicians with high $(\geq 60 \%, n=16)$ and low $(\leq 45 \%, n=8)$ CRC screening rates (based on HEDIS criteria). We conducted no statistical tests because of the small sample size and its exploratory aims.

Results: High screeners used dramatic language (eg, patient stories) and mentioned risk of death, disability, or surgery from CRC in screening discussion role-plays more often than low screeners. High screeners frequently offered fecal occult blood testing, flexible sigmoidoscopy, and colonoscopy as equally acceptable screening options. High screeners more commonly described solutions for overcoming CRC screening barriers.

Conclusions: Encouraging providers to use risk-specific messaging about the consequences of CRC, offering screening option choices, and promoting a problem-solving approach to surmount barriers are potential strategies for increasing CRC screening rates. (J Am Board Fam Med 2012;25:771-781.)

Keywords: Cancer Screening, Colorectal Cancer, Delivery of Health Care, Doctor Patient Relations

More than 50,000 Americans will die from colorectal cancer (CRC) in 2010, and another 100,000 will need surgery or other treatment to survive. ${ }^{1}$ Screening can decrease the mortality and morbidity of CRC. . $^{2-6}$ CRC screening rates have been increasing: in 2010, $65.4 \%$ of people aged 50 to 75 years reported being up to date with CRC screening, compared with $52.3 \%$ in

This article was externally peer reviewed.

Submitted 23 September 2011; revised 15 February 2012; accepted 26 March 2012.

From the Department of Family Medicine, University of Washington, Seattle (CMO, LMB); the Group Health Research Institute, Seattle, WA (BG, RR); and the Department of Community Health Sciences, Boston University, Boston, MA (DB).

Current affiliation: Swedish Medical Group, Seattle, WA (CMO).

Funding: This project was funded by the Centers for Disease Control and Prevention (CDC) through the University of Washington Health Promotion Research Centers Cooperative Agreement U48DP001911; and through the Alliance for Reducing Cancer, Northwest (ARC NW), funded by both the CDC (grant U48DP001911) and the National Cancer Institute (NCI).
2002..$^{7}$ Although these numbers are encouraging, rates remain significantly lower than those reported for breast and cervical cancer screening, ${ }^{6}$ and almost $30 \%$ of eligible adults report never having any CRC screening. ${ }^{8}$

Physician recommendation is an important predictor of CRC screening. ${ }^{9}$ Although more than $99 \%$ of physicians report routinely recommending CRC screening with at least one type of test, ${ }^{10}$ many eligible patients (21.4\% to $52.7 \%$ ) report not receiving this recommendation, ${ }^{11,12}$ and many are not screened. Even when a recommendation for CRC screening is made, there is room for substan-

Conflict of interest: none declared.

Disclaimer: The findings and conclusions of this journal article are those of the authors and do not necessarily represent the official position of the Centers for Disease Control and Prevention.

Corresponding author: Laura-Mae Baldwin, MD, MPH, Department of Family Medicine, University of Washington, Box 354982, Seattle, WA 98195-4982 (E-mail: lmb@uw.edu). 
tial variation in its content and presentation. A full discussion of the risks, benefits, and screening options may require up to 45 minutes, exceeding the length of an average clinic visit. ${ }^{13}$

A recent large survey of US primary care physicians ${ }^{10}$ and a qualitative analysis of audiotaped discussions between physicians and patients ${ }^{14}$ found that community physicians recommended colonoscopy more often than other CRC screening tests, which may forfeit screening opportunities for patients who decline colonoscopy. Several qualitative studies have explored the physician-patient CRC screening discussion, such as the use of the 5 As framework (assess, advise, agree, assist, and arrange); barriers and facilitators to physicians making a CRC screening recommendation; and strategies physicians use to encourage CRC screening, but most have not linked their findings with actual CRC screening rates. ${ }^{14-19}$ We found 2 studies that audiotaped physician-patient CRC screening discussions to identify specific discussion elements, then measured CRC screening completion after these discussions. Ling et $\mathrm{al}^{20}$ focused on informed decision making during CRC screening discussions and found overall low levels of informed decision making and a negative relationship between certain informed decision-making discussion elements and CRC screening. Fenton and colleagues ${ }^{21}$ focused on the degree to which physicians addressed behavioral constructs, such as patient self-efficacy, in their CRC screening discussions. They found that completion of CRC screening was positively associated with physician discussion of CRC screening but not with counseling related to the specific CRC screening-related behavioral constructs. Audiotapes provide objective documentation of the CRC screening discussion content but do not examine physicians' experiences and beliefs about CRC screening, which are factors that could influence the screening discussion.

This study builds on this literature by conducting semistructured interviews with physicians to solicit their experiences with CRC screening and by role playing with them to examine how physicians recommend and discuss CRC screening with their average-risk patients. We measured the physicians' CRC screening rates and explored the relationship between these rates and the content of these discussions and physicians' CRC screening experiences. This information can help shape effective physician- and practice-based interventions aimed at increasing uptake of CRC screening among average-risk patients.

\section{Methods}

This study identified physicians with high and low CRC screening rates in their practices, interviewed these physicians about their CRC screening patterns, and looked for relationships between the themes identified in the interviews and the physicians' CRC screening rates. We used utilization data extracted from electronic medical records to identify the groups of physicians with the highest and lowest CRC screening rates. ${ }^{22}$ An interviewer (CMO) masked to these rates conducted semistructured interviews with these physicians about their approach to discussing CRC screening with their patients and the factors influencing their discussions. We used the physician interview data to explore whether specific elements from the physicians' self-reported CRC screening discussions might be associated with high or low CRC screening rates.

\section{Setting}

The study was conducted at Group Health Cooperative, a large, nonprofit, integrated delivery system that provides medical coverage and care to more than 600,000 members in the states of Washington and Idaho. Conducting this study in a single integrated health system held constant factors that might influence CRC screening rates, such as patient access, provider incentives, coverage for services, organizational education, and patient incentives. Adult health care at Group Health's 26 clinics is provided by family physicians $(90 \%)$ and internists $(10 \%)$, more than $95 \%$ of whom are board certified. In 2007, each full-time physician cared for an average panel of 2200 patients. Clinics are divided into teams of 3 to 4 physicians, a physician assistant or nurse practitioner, and registered nurses, licensed practical nurses, and medical assistants. Group Health utilizes a system-wide electronic medical record (Epic, Epic Systems Corp, Verona, WI) that tracks encounters, procedures, test results, and medications. Providers have access to internal evidence-based clinical practice guidelines and supporting patient education materials about CRC screening. Patients have access to a secure Web site (MyGroupHealth), which allows them to send secure Emails to their providers, review test results and por- 
tions of their medical record, and access information about CRC screening.

Group Health instituted an evidence-based CRC screening guideline in 1982 that has been updated every 2 years based on systematic reviews of evidence and consideration of national recommendations. When this study was conducted, Group Health's CRC screening guideline recommended that average-risk adults ages 50 to 79 years receive yearly fecal occult blood testing (FOBT) and flexible sigmoidoscopy (FS) every 10 years. Colonoscopy was an option for averagerisk patients after shared decision making with their physicians. Throughout the study, all inperson office visits, including preventive examinations, lasted approximately 20 minutes.

\section{Study Population}

Study physicians were drawn from the 178 family physicians and general internists who worked within 21 clinics owned by Group Health in the Puget Sound region throughout 2005 and had at least 50 patients who were eligible for CRC screening. Resident physicians were excluded. CRC screening rates were calculated for each physician's patient panel in 2005 using the National Committee for Quality Assurance Healthcare Effectiveness Data and Information Set criteria at the time of the study. To meet Healthcare Effectiveness Data and Information Set criteria for CRC screening, all patients ages 50 to 80 years, excluding those with a history of CRC or total colectomy, were required to have received FOBT during the measurement year (2005), FS or double-contrast barium enema during the measurement year or the 4 years before, or colonoscopy during the measurement year or the 9 years before. We examined the distribution of calculated physician-specific CRC screening rates and selected physicians in the highest and lowest CRC screening rate sextiles. We chose physicians at the extremes of screening rates to illuminate distinguishing features of CRC screening discussions. ${ }^{23,24} \mathrm{We}$ designated the 29 physicians with $\geq 60 \%$ CRC screening rates as having high screening rates (high screeners) and the 22 physicians with rates of $\leq 45 \%$ as having low screening rates (low screeners). The screening rates of the 51 physicians were masked to the screening rate, and the list of physicians was sent to one of the authors (CMO) for recruitment to qualitative interviews. Five physicians were no longer employed at Group
Health at that time, leaving 46 potential physician study participants.

\section{Study Instruments}

The study team developed a semistructured interview guide with 15 questions and 56 probes (available upon request from corresponding author $[\mathrm{LMB}])$. The interview included a request for the physician to role play the CRC screening discussion, with the interviewer acting as a patient at average risk for CRC. The interview guide's questions and prompts were designed to gather evidence about topics that the theoretical model, Ajzen's Theory of Planned Behavior, ${ }^{25}$ and prior research $^{26-30}$ suggested could be associated with variation in CRC screening rates in physicians' practices. Nine topics formed the basis for each interview: visit agenda setting, the screening message the provider presented to patients, the physician's perceived role in the CRC screening discussion, facilitators and barriers to discussions about CRC screening and to CRC screening itself, reminder systems used in CRC screening, FS training, perceived advantages and disadvantages of CRC screening, physician views on CRC screening guidelines, and personal experiences with CRC and CRC screening. The interview guide was tested for length and clarity with 4 physicians who did not work within Group Health. A 9-item written questionnaire administered after the interview gathered information such as physicians' medical specialty; years practicing at Group Health; types and frequency of CRC screening tests offered to average-risk patients, and knowledge of CRC screening guidelines (available upon request from corresponding author [LMB]).

\section{Study Procedures}

Three E-mail invitations were sent to 46 eligible physicians, requesting participation in the 1 -hour interview. After obtaining informed consent, a study author (CMO) conducted and audiotaped the interviews with consenting physicians in person or via telephone between July and December 2007. Neither the interviewer nor the physician subjects were aware of the physicians' status as high or low CRC screeners. Each participant received a $\$ 100$ honorarium. Three interviews were not recorded successfully. For these, the interviewer dictated the physician's responses immediately following the interview. We used data from all 24 subjects to describe physician recommendations for the type of 
CRC screening tests because the interview data could be confirmed with written questionnaire data. For the remainder of the qualitative analysis, we used data from the 21 audiotaped interviews. All study procedures were approved by the Group Health Institutional Review Board.

\section{Analysis}

After completing all interviews, we conducted analysis on the verbatim, de-identified transcripts using Atlas.ti software (Atlas.ti Scientific Software Development Gmbh, Berlin, Germany). All coders were blinded to the physicians' status as high or low screeners throughout the qualitative analysis. On the basis of the interview question topics and an initial assessment of the interview responses, two authors (CMO and LMB) defined broad category codes for classifying the transcripts: screening message, screening beliefs, facilitators and barriers to screening, personal experiences, screening guidelines, agenda setting, staff involvement, role, style, and recommendation. This allowed for the categorization of all physician comments even if the quotation occurred out of sequence in the interview. Using these codes, the 2 authors independently coded 2 complete interview transcripts and used an iterative process to augment and refine the category codes with additional transcripts. Some category codes were identical to the initial interview topics, whereas others were derived from interview responses. After there was agreement on the category definitions, the 2 authors independently coded all 24 transcripts, resolving any discrepancies through discussion. We assigned all quotations to at least one category.

Next, one author (CMO) developed a preliminary list of themes drawn directly from the categorized quotations. ${ }^{24}$ In all categories, at least 2 other authors participated in an iterative process to revise and define existing themes, develop new themes, and resolve discrepancies in the assignment of a quotation to one or more themes. Five categories had substantial variation in the identified themes: screening message recommendation, screening message style, facilitators of and barriers to CRC screening, screening guidelines, and personal experience with cancer and screening. After completing this qualitative analysis, we linked its results to designation of the physician as a high or low screener. We examined similarities and differences in physician and practice characteristics among physicians in the 2 screening groups using physi- cian survey data. We examined the frequency of each theme among the high and low screeners, looking for potential relationships and choosing quotations to illustrate themes. Because this is an exploratory study among a small number of physicians, we did not conduct statistical tests to compare high and low screening groups.

\section{Results}

Of the 46 eligible physicians, 24 (52\%) provided informed consent and completed the interview. Of the 24 interviews, 8 had low CRC screening rates (all $<45 \%$, average of $42 \%$ ), and 16 had high rates (all $>60 \%$, average of $65 \%$ ). Post hoc analysis found the participation rate was $42 \%$ (8 of 19) for physicians with low screening rates and 59\% (16 of 27) for physicians with high screening rates. Because 3 interviews were not successfully audiotaped, complete interview data are available for 7 physicians in the low screening group and 14 physicians in the high screening group.

The high and low screeners had similar demographic and practice characteristics (Table 1). On average, physicians were employed at Group Health for 15 years. Three of the 24 were internal medicine physicians (12\%), consistent with the overall proportion of primary care internal medicine physicians (10\%) at Group Health. Thirteen of 14 high screeners reported being eligible for CRC screening, with 10 reporting that they had received FS or colonoscopy (data not shown). Five of 7 low screeners reported being eligible, and 2 had undergone FS or colonoscopy. We focused the interview results on those themes that distinguished between high and low screeners: the screening message recommendations, the style with which the physician delivered CRC screening messages, barriers to and facilitators of CRC screening, and views on the differences between Group Health and national organizations' CRC screening recommendations.

\section{CRC Screening Message Recommendation}

The physicians reported recommending CRC screening using 3 approaches (Table 2):

1. FOBT and FS offered first, with colonoscopy offered secondarily

2. FOBT, FS, and colonoscopy offered simultaneously and neutrally

3. Colonoscopy recommended as a first step 


\begin{tabular}{|c|c|c|}
\hline \multirow[b]{2}{*}{ Characteristics } & \multicolumn{2}{|c|}{ Physician Group } \\
\hline & $\begin{array}{l}\text { Low Screeners* } \\
\qquad(\mathrm{n}=8)\end{array}$ & $\begin{array}{l}\text { High Screeners } \\
\text { (n }=16)\end{array}$ \\
\hline Patients in the physician's panel who are eligible for CRC screening, ${ }^{\ddagger} \mathrm{n}$ (range) & $547(96-928)$ & $545(73-944)$ \\
\hline Patients screened for CRC in 2005 (range) & $42.1(38.3-44.9)$ & $64.8(60.9-70.2)$ \\
\hline \multicolumn{3}{|l|}{ Physician demographics } \\
\hline Year graduated from medical school (range) & $1984(1970-2001)$ & $1982(1972-1998)$ \\
\hline Men & 75.0 & 50.0 \\
\hline \multicolumn{3}{|l|}{ Training and practice characteristics } \\
\hline Years employed at Group Health, n (range) & $15(1.5-23)$ & $17(3-30)$ \\
\hline \multicolumn{3}{|l|}{ Panel patients by age } \\
\hline $0-18$ years & 12.6 & 10.9 \\
\hline $19-49$ years & 46.7 & 42.8 \\
\hline $50-64$ years & 28.2 & 30.6 \\
\hline $65-79$ years & 9.4 & 10.8 \\
\hline$\geq 80$ years & 3.1 & 4.9 \\
\hline Patients seen each week, mean $\mathrm{n}$ (range) ${ }^{\S}$ & $75(40-95)$ & $67(50-100)$ \\
\hline Trained in flexible sigmoidoscopy" & 100.0 & 100.0 \\
\hline Performed flexible sigmoidoscopy & 12.5 & 18.8 \\
\hline
\end{tabular}

Values provided as percentages unless otherwise indicated.

*Low screeners are the physicians whose patient panels had CRC screening rates of $\leq 45 \%$.

${ }^{\dagger}$ High screeners are the physicians whose patient panels had CRC screening rates of $\geq 60 \%$.

†Based on HEDIS criteria: number of patients in the physician's panel aged 50 to 80 years on December 31, 2005, and continuously enrolled in 2005 with no more than one gap in continuous enrollment of up to 45 days. Individuals with colorectal cancer and with total colectomy were excluded.

${ }^{\$}$ Both part-time and full-time physicians were included as long as they had at least 50 patients eligible for CRC screening in 2005. "At the time of this study, most flexible sigmoidoscopy procedures were centralized at Group Health and were performed by physician assistants, nurse practitioners, or gastroenterologists.

CRC, colorectal cancer.

Approximately $50 \%$ of both the high and low screeners first offered FOBT and FS and discussed colonoscopy as a secondary option (the recommended Group Health guideline). However, all the remaining high screeners, but only a quarter of the low screeners, reported recommending FOBT, FS, and colonoscopy as equally acceptable options. The only 2 physicians who recommended colonoscopy as the preferred screening option were low screeners.

\section{Style of Delivering the CRC Screening Message}

We identified several themes that described the style with which physicians reported delivering CRC screening messages. The majority of high and low screeners were coded as delivering CRC screening messages in an engaged style, indicated by a high level of enthusiasm for CRC screening (Table 3). High screeners were coded more often as dramatic in their delivery style, using stronger descriptive language and patient stories to emphasize the importance of CRC screening. This is consis- tent with the finding that 9 of the 14 high screeners but only 1 of the 7 low screeners used specific language that the analysis team defined as "consequence messaging" in the CRC screening discussions: describing adverse outcomes associated with CRC, such as death, disability, or surgery. Low screeners were classified as directive more often than high screeners, defined as giving patients clear, unequivocal information, advice, or recommendations about CRC screening. We directly asked physicians how they defined their role in the CRC discussion. Physicians' self-identified role did not distinguish high and low screeners, nor was role associated with physicians' style of delivering the CRC screening message; almost all physicians (18 of 21) identified themselves as "educators."

Some physicians were characterized as "problem solvers" because they offered a practical solution after describing a CRC screening barrier, such as reminding patients to schedule preventive care visits, using reports to identify patients who are not current with 
Table 2. Colorectal Cancer Screening Message Recommendation of Low and High Screeners $(n=24)$

\begin{tabular}{|c|c|c|c|c|}
\hline \multirow[b]{2}{*}{$\begin{array}{l}\text { Screening Message } \\
\text { Recommendation }\end{array}$} & \multicolumn{2}{|c|}{ Physician Group } & \multirow[b]{2}{*}{$\begin{array}{c}\text { Total } \\
(\mathrm{n}=24)\end{array}$} & \multirow[b]{2}{*}{ Illustrative Quotations } \\
\hline & $\begin{array}{l}\text { Low Screeners } \\
\qquad(\mathrm{n}=8)\end{array}$ & $\begin{array}{l}\text { High Screeners } \\
\qquad(\mathrm{n}=16)\end{array}$ & & \\
\hline $\begin{array}{l}\text { Colonoscopy } \\
\text { recommended, with } \\
\text { colonoscopy offered } \\
\text { secondarily }\end{array}$ & $4(50.0)$ & $7(43.8)$ & $11(45.8)$ & $\begin{array}{l}\text { "Well I tell them about doing a hemoccult test } \\
\text { first, that that's the established way and very } \\
\text { effective way to determine whether you } \\
\text { should have a sigmoidoscopy or } \\
\text { colonoscopy, if result is positive. And so we } \\
\text { talk about that - the hemoccult test that they } \\
\text { do at home; and the fact that if it shows } \\
\text { blood, they need to have a complete } \\
\text { visualization of their colon. But if there's not } \\
\text { blood, they can just do the } \\
\text { sigmoidoscopy....And then there are also } \\
\text { people who want a colonoscopy.... I'm not } \\
\text { gonna argue with someone like that." }\end{array}$ \\
\hline $\begin{array}{l}\text { FOBT, FS, colonoscopy all } \\
\text { offered simultaneously } \\
\text { and neutrally }\end{array}$ & $2(25.0)$ & $9(56.3)$ & $11(45.8)$ & $\begin{array}{l}\text { "Now, there's three different possibilities for } \\
\text { screening. There's the sort of least, easiest, } \\
\text { least invasive thing, but it has to be done } \\
\text { every year, and that would be, um, doing, } \\
\text { um, stool occult blood cards....Um, the next } \\
\text { option is a combination of doing the stool } \\
\text { hemoccult. If they're positive you do a, um, } \\
\text { colonoscopy; if they're negative then we do } \\
\text { something called a "flexible sigmoidoscopy,' } \\
\text { and this is actually the approach that Group } \\
\text { Health recommends....And then the other } \\
\text { option is a colonoscopy, and that's the most } \\
\text { invasive test, but it's also one that is only } \\
\text { done every } 10 \text { years. And if it's normal, you } \\
\text { don't have to do anything in between." }\end{array}$ \\
\hline $\begin{array}{l}\text { Colonoscopy recommended } \\
\text { as first step }\end{array}$ & $2(25.0)$ & $0(0)$ & $2(8.3)$ & $\begin{array}{l}\text { "I tell patients, "if you really wanna have the } \\
\text { best test that you can have right now-that } \\
\text { you know is more invasive, but it's better as } \\
\text { far as ruling in or out any disease-you } \\
\text { should have a colonoscopy. And if it is } \\
\text { normal then you don't need to do anything } \\
\text { for } 10 \text { years. That is the beauty of it. } \\
\text { Whereas if you do the other tests you have } \\
\text { to keep repeating them. And my view of } \\
\text { that, "cause I used to do sigmoidoscopy, is I } \\
\text { think that's a wasted step; you might as well } \\
\text { go straight to colonoscopy."” }\end{array}$ \\
\hline
\end{tabular}

Values provided as $\mathrm{n}(\%)$.

FOBT, fecal occult blood testing; FS, flexible sigmoidoscopy.

CRC screening, providing patient education materials about CRC screening, and empowering staff to help identify patients due for screening. Ten of the 14 high screeners were problem solvers, but only 2 of the 7 low screeners were the same.

\section{Physician CRC Screening and Diagnosis Experience}

Most high screeners (12 of 14) but the minority of low screeners ( 2 of 7 ) reported having patients with a complication or adverse event related to screening. The complications and adverse events reported by both high and low screeners were similar and included perforation, bleeding, bloating, and pain. The majority of all physicians reported having pa- tients diagnosed with CRC (18 of 21 physicians: 12 of 14 high screeners, 6 of 7 low screeners) and close friends or family members diagnosed with either colorectal polyps or CRC (17 of 21 physicians: 12 of 14 high screeners, 5 of 7 low screeners).

\section{Barriers to and Facilitators of CRC Screening}

Most physicians did not distinguish between barriers to and facilitators of screening versus the delivery of the CRC screening message, so these results are presented together. Table 4 demonstrates that, overall, physicians reported as many barriers (4.8) as facilitators (4.2). On average, high screeners reported more facilitators (5.0) than low screen- 
Table 3. Style of Delivering the Colorectal Cancer Screening Message $(n=21)$

\begin{tabular}{|c|c|c|c|c|}
\hline \multirow[b]{2}{*}{ Style } & \multicolumn{2}{|c|}{ Physician Group } & \multirow[b]{2}{*}{$\begin{array}{c}\text { Total } \\
(\mathrm{n}=21)\end{array}$} & \multirow[b]{2}{*}{ Illustrative Quotations } \\
\hline & $\begin{array}{l}\text { Low Screeners } \\
\quad(\mathrm{n}=7)\end{array}$ & $\begin{array}{l}\text { High Screeners } \\
\quad(\mathrm{n}=14)\end{array}$ & & \\
\hline Engaged* & $5(71.4)$ & $10(71.4)$ & $15(71.4)$ & \multirow[b]{2}{*}{$\begin{array}{l}\text { Quote from engaged subject: "I learned a long time } \\
\text { ago that a lot of times you can.... what we now } \\
\text { call "opportunistic care." You know, I almost did } \\
\text { a physical on someone that came in for elbow } \\
\text { pain...try to click on this little screen and figure } \\
\text { out whether their health maintenance is up...It's } \\
\text { a little hobby on the side. All that screening and } \\
\text { prevention is great. So the advantage is you feel } \\
\text { like you are doing a good job. And for the } \\
\text { patient, hopefully you catch a few patients and } \\
\text { you do something positive. And on colon cancer } \\
\text { you feel real good that it happened." }\end{array}$} \\
\hline Nonengaged & $2(28.6)$ & $4(28.6)$ & $6(28.6)$ & \\
\hline Dramatic $^{\dagger}$ & $1(14.3)$ & $10(71.4)$ & $11(52.4)$ & \multirow[b]{2}{*}{$\begin{array}{l}\text { Quote from dramatic subject: "I had a woman who } \\
\text { was about } 56 \text { or so who'd never had screening. } \\
\text { And she had a sigmoidoscopy and they found a } \\
\text { very small polyp that turned out to be cancerous. } \\
\text { And she just had to have a short segment of her } \\
\text { colon removed. And I said, "If she hadn't agreed } \\
\text { to have this, by the time she'd finally been } \\
\text { screened, it could've been too late.' So I have } \\
\text { often used that as an example of why it's } \\
\text { important to do it." }\end{array}$} \\
\hline Nondramatic & $6(85.7)$ & $4(28.6)$ & $10(47.6)$ & \\
\hline Directive $^{\ddagger}$ & $5(71.4)$ & $3(21.4)$ & $8(38.1)$ & \multirow{2}{*}{$\begin{array}{l}\text { Quote from directive subject: "I initiate the } \\
\text { screening discussion. Then I clarify information. } \\
\text { Then I offer the best options for patients. And if } \\
\text { they say, "Well, I'm not sure,' then I say, "I } \\
\text { would recommend a flexible sigmoidoscopy." }\end{array}$} \\
\hline Nondirective & $2(28.6)$ & $11(78.6)$ & $13(61.9)$ & \\
\hline Consequence messaging $^{\S}$ & $1(14.3)$ & $9(64.3)$ & $10(47.6)$ & \multirow[b]{2}{*}{$\begin{array}{l}\text { Quote using consequence messaging: "It's really } \\
\text { pretty important. It's as good as mammography, } \\
\text { or better, in a sense that if you catch this illness } \\
\text { early, you're gonna get it cured....And it grows } \\
\text { very slowly. And so, if you catch it early, you're } \\
\text { definitely gonna be saved a miserable death. And } \\
\text { we're all gonna go some time. But going with } \\
\text { cancer's no good." }\end{array}$} \\
\hline No consequence messaging & $6(85.7)$ & $5(35.7)$ & $11(52.4)$ & \\
\hline Problem solver ${ }^{\|}$ & $2(28.6)$ & $10(71.4)$ & $12(57.1)$ & \multirow{2}{*}{$\begin{array}{l}\text { Quote from problem solver: "The hardest part is } \\
\text { the prep....So I usually tell my patients "Get a } \\
\text { little Kool-Aid packet. Get the lemon one and } \\
\text { sprinkle it on the top and chug-a-lug and it's not } \\
\text { so bad.". }\end{array}$} \\
\hline Nonproblem solver & $5(71.4)$ & $4(28.6)$ & $9(42.9)$ & \\
\hline
\end{tabular}

Values provided as $\mathrm{n}(\%)$.

*Engaged/nonengaged describe the enthusiasm the physician expressed for his/her beliefs about colorectal cancer (CRC) screening.

${ }^{\dagger}$ Dramatic/nondramatic describe the type of descriptive language and patient stories that the physician reported using when discussing CRC screening with patients.

${ }^{\ddagger}$ Directive/nondirective describe the level of clarity the physician demonstrated in determining the agenda or providing information, advice, or recommendations about CRC screening.

${ }^{\$}$ Consequence messaging indicates that the physician warns the patient of the risk of death, disability, or surgery as a result of CRC. "Problem solvers discuss a solution to identified barriers to CRC screening.

ers (2.6). However, they also reported more barriers (5.2) than low screeners (4.1). Several barriers were reported by at least half of both groups, though a disproportionately larger number of low screeners ( 4 of 7 ) mentioned patient reluctance compared with high screeners (1 of 14). At least half of both groups indicated the electronic medical record as a facilitator. High screeners commonly mentioned staff assistance, patient questions, and a scheduled general physical examination as facilitators.

\section{Differences between Group Health and National Organizations' CRC Screening Recommendations}

Overall, 10 of 21 respondents commented on the differences between Group Health's and other national organizations' guidelines. When the study took place, Group Health recommended FS every 
Table 4. Barriers to and Facilitators of Colorectal Cancer (CRC) Screening and CRC Screening Message Delivery

\begin{tabular}{|c|c|c|c|}
\hline & \multicolumn{2}{|c|}{ Physician Group } & \multirow[b]{2}{*}{$\begin{array}{c}\text { Total } \\
(\mathrm{n}=21)\end{array}$} \\
\hline & $\begin{array}{l}\text { Low Screeners } \\
\qquad(\mathrm{n}=7)\end{array}$ & $\begin{array}{l}\text { High Screeners } \\
\qquad(\mathrm{n}=14)\end{array}$ & \\
\hline \multicolumn{4}{|l|}{ Facilitators } \\
\hline $\begin{array}{l}\text { Mentioned per } \\
\text { interview, mean n } \\
\text { (range) }\end{array}$ & $2.6(2-3)$ & $5.0(2-7)$ & $4.2(2-7)$ \\
\hline $\begin{array}{l}\text { Mentioned by at least } \\
\text { half of physicians }\end{array}$ & EMR & $\begin{array}{l}\text { EMR } \\
\text { Clinic staff assistance } \\
\text { Patient has question about any GI or } \\
\text { prevention topic } \\
\text { Scheduling preventive visits } \\
\text { Patient has information from public or } \\
\text { familial source about CRC }\end{array}$ & \\
\hline \multicolumn{4}{|l|}{ Barriers } \\
\hline $\begin{array}{l}\text { Mentioned per } \\
\text { interview, mean n } \\
\text { (range) }\end{array}$ & $4.1(3-6)$ & $5.2(2-8)$ & $4.8(2-8)$ \\
\hline $\begin{array}{l}\text { Mentioned by at least } \\
\text { half of physicians }\end{array}$ & $\begin{array}{l}\text { Test discomfort/pain } \\
\text { Difficult to track incomplete screening } \\
\text { Too little appointment time } \\
\text { Reluctant patients }\end{array}$ & $\begin{array}{l}\text { Test discomfort and pain } \\
\text { Difficult to track incomplete screening } \\
\text { Too little appointment time } \\
\text { Inconvenient for patient } \\
\text { Test preparation difficult } \\
\text { Patient has too many problems to take } \\
\text { care of at visit } \\
\text { Lack of EMR pop-up reminder } \\
\text { High cost of screening }\end{array}$ & \\
\hline $\begin{array}{l}\text { Total facilitators and } \\
\text { barriers per interview, } \\
\text { mean } \mathrm{n} \text { (range) }\end{array}$ & $6.7(5-8)$ & $10.2(4-14)$ & $9.0(4-14)$ \\
\hline
\end{tabular}

EMR, electronic medical record; GI, gastrointestinal.

10 years, whereas community standards tended to recommend this test every 5 years. More high screeners ( 8 of 14 ) than low screeners ( 2 of 7 ) commented on this difference. The following quotation illustrates one physician's conflict about CRC guideline discrepancies:

"Well I think there is a discrepancy between our guidelines and private practice. So I can't speak for community standard, but an awful lot of my patients coming from outside of Group Health had had their colonoscopy at age 50. I don't know if that's the right thing to do, but I frequently talk to my patients about, we don't quite know what the right thing to do is. And perhaps, you know, a one-time colonoscopy is a good idea. We don't know.... So I guess I'm more in line with the national guidelines. But I really offer both.... It makes me a little bit nervous just getting by with [FS], because we're seeing polyps all the time."

\section{Discussion}

This study suggests that high screeners may approach the CRC screening discussion with average- risk patients differently than low screeners. Although most physicians used an engaged style in their CRC screening discussions, high screeners were more likely to be dramatic and mention the possibility of death, disability, or surgery as a consequence of CRC. The tendency for high screeners to use dramatic language supports the findings of Fox et $\mathrm{al}^{31}$ that patients who perceived their physicians to be enthusiastic during their CRC screening discussions were more likely to report having been screened. These findings also are consistent with studies of "message framing" that have demonstrated that messages about cancer screening framed as loss increase patients' intentions to get screened compared with messages framed as gains $^{32,33}$ and that messages framed as gains increase in effectiveness if the message implies emotional relief after screening. ${ }^{34}$

High screeners seemed to be less directive in their discussions, frequently initially offering FOBT, FS, and colonoscopy as equally viable options. A national survey found that this is not usual practice, however, with only 
about $15 \%$ of primary care physicians usually offering all 3 CRC screening options. ${ }^{35}$ Individuals who are allowed to choose are more likely to complete a task than those who are denied options. ${ }^{36-38}$ Shokar et $\mathrm{al}^{13}$ confirmed that preferences for CRC screening tests vary by age, sex, race, and ethnicity, with choices reflecting individuals' unique experiences. Further research is needed to evaluate whether, as our study suggests, dramatic messaging, discussing the consequences of CRC, and neutrally presenting 3 test options for CRC screening may be effective, time-efficient ways to increase CRC screening uptake.

In contrast to current national trends, colonoscopy was not endorsed over other screening methods ${ }^{10}$ by most physicians in this study. This may reflect the fact that Group Health's evidence-based guidelines at the time of the study did not rate the evidence as strongly for colonoscopy as for FOBT or FS. Despite the publication of such institutional guidelines, Group Health physicians are at liberty to discuss the full range of CRC screening options, and, as this study demonstrates, many did. It is interesting that the only 2 physicians who recommended colonoscopy as the initial CRC screening strategy were low screeners. This is consistent with the qualitative analysis of audiotaped physicianpatient discussions by McQueen et $\mathrm{al},{ }^{14}$ which found that physicians who regularly recommended CRC screening but focused on colonoscopy generally ignored patients' specific requests for FOBT or FS, despite patient concerns about colonoscopy, such as risks and costs. Further research is needed to explore whether the increasing prominence of colonoscopy as a CRC screening strategy discourages some patients from CRC screening.

The finding that high screeners frequently mentioned a solution to a CRC screening barrier suggests that they believed these barriers could be overcome. This implies that one element of Ajzen's Theory of Planned Behavior, the strength of a physician's belief that he or she can control factors that facilitate or impede, in this case, CRC screening, ${ }^{25}$ may promote screening. This matches the findings of Carpiano et $\mathrm{al}^{39}$ of an association between physician tenacity and increased delivery of preventive services. In fact, several of the barriers to and facilitators of CRC screening mentioned by high (and sometimes low) screeners have been associated with use of cancer screening tests. In particular, use of the electronic medical record to identify underscreened individuals, electronic medical record "pop-ups" or clinical decision support tools at the point of clinical care, and team-based care involving clinical staff members with specific cancer screening responsibilities are all effective strategies themselves or components of effective strategies to increase cancer screening rates. ${ }^{40-42}$

Our study has several noteworthy limitations. Our sample size is small, and only half of the physicians we approached agreed to be interviewed. Because of this small sample size and the exploratory nature of this study, we did not conduct statistical tests to compare the findings for high and low screeners. This study compared physicians whose practices were at the low and high ends of CRC screening rates and thus may not represent physicians with average screening rates. We experienced technical problems with 3 audiotapes and limited most of our results to the 21 recorded interviews. This study relied on physician self-report of CRC screening discussions, which may differ from medical records or what patients report. ${ }^{43}$ We did not audiotape actual patient visits; physicians might perform differently in patient encounters. Although the Group Health CRC screening guideline did not change during the study, a lag in the availability of data meant study screening rates were calculated for 2005, 2 years before the 2007 interviews.

Other limitations relate to the conduct of this study in a single integrated health system. This could have led to less variation in physicians' CRC screening rates than in community practice. Because Group Health provides care mainly to patients with employee-based insurance plans or Medicare, our findings may not be broadly representative. Findings may differ by practice geographic location, size, and organization and for physicians who care for uninsured patients. ${ }^{44}$ In addition, Group Health patients generally are assigned to one primary care physician and have access to online information about CRC screening options. This could have decreased variation in the answers to some interview questions. Nevertheless, even within a highly integrated health system, there may be important differences between clinics and between physicians' patient populations (eg, demographics) that could influence screening rates. There were also advantages to conducting this study in a single health system like Group Health because this system maintains constant factors that 
might influence CRC screening rates, such as patient access, provider incentives, coverage for services, organizational education, and patient incentives. Last, a particular strength of this study is its mixed-method design, which directly linked physician screening rates with data of physician-reported physician-patient CRC screening discussions.

\section{Conclusions}

This exploratory study suggests potential differences between physicians with high and low rates of CRC screening. High screeners seemed to be more likely than low screeners to offer 3 CRC screening test options. They tended to use more dramatic language, including directly mentioning death, disability, or surgery as a consequence of CRC. They were less directive in their role playing of the physician-patient CRC screening discussion. High screeners were more likely to discuss solutions to barriers in CRC screening, many of which are conducive to implementation through a team care approach. Future studies that link physician CRC screening rates to direct observation of physicianpatient CRC screening discussions are needed to confirm these findings. Our results also suggest the need for studies that examine whether CRC screening rates can be increased by provider interventions that encourage the use of risk-specific messaging about the consequences of CRC, promote a problem solving approach, and offer FOBT, FS, and colonoscopy as equally acceptable screening options.

The authors thank 2 individuals from the Group Health Research Institute: David Carrell for computer programming and Kelly Ehrlich for project management. They also thank the Group Health physicians who shared their clinical practice approaches.

\section{References}

1. American Cancer Society. Colorectal cancer facts and figures 2008-2010. Atlanta, GA: American Cancer Society; 2008.

2. Atkin WS, Cuzick J, Northover JM, Whynes DK. Prevention of colorectal cancer by once-only sigmoidoscopy. Lancet 1993;341:736-40.

3. Hewitson P, Glasziou P, Irwig L, Towler B, Watson E. Screening for colorectal cancer using the faecal occult blood test, hemoccult. Cochrane Database Syst Rev 2007;(1):CD001216.

4. Mandel JS, Church TR, Bond JH, et al. The effect of fecal occult-blood screening on the incidence of colorectal cancer. N Engl J Med 2000;343:1603-7.
5. U.S. Preventive Services Task Force. Screening for colorectal cancer. AHRQ Publication 08-05124-F-3. Rockville, MD: Agency for Healthcare Research and Quality; 2008.

6. Winawer S, Fletcher R, Rex D, et al. Colorectal cancer screening and surveillance: clinical guidelines and rationale-update based on new evidence. Gastroenterology 2003;124:544-60.

7. Vital signs: colorectal cancer screening, incidence, and mortality-United States, 2002-2010. MMWR Morb Mortal Wkly Rep 2011;60:884-9.

8. Smith RA, Cokkinides V, Brooks D, Saslow D, Brawley OW. Cancer screening in the United States, 2010: a review of current American Cancer Society guidelines and issues in cancer screening. CA Cancer J Clin 2010;60:99-119.

9. Gilbert A, Kanarek N. Colorectal cancer screening: physician recommendation is influential advice to Marylanders. Prev Med 2005;41:367-79.

10. Klabunde CN, Lanier D, Nadel MR, McLeod C, Yuan G, Vernon SW. Colorectal cancer screening by primary care physicians: recommendations and practices, 2006-2007. Am J Prev Med 2009;37:8-16.

11. DuBard CA, Schmid D, Yow A, Rogers AB, Lawrence WW. Recommendation for and receipt of cancer screenings among Medicaid recipients 50 years and older. Arch Intern Med 2008;168:2014-21.

12. Klabunde CN, Meissner HI, Wooten KG, Breen N, Singleton JA. Comparing colorectal cancer screening and immunization status in older Americans. Am J Prev Med 2007;33:1-8.

13. Shokar NK, Carlson CA, Weller SC. Informed decision making changes test preferences for colorectal cancer screening in a diverse population. Ann Fam Med 2010;8:141-50.

14. McQueen A, Bartholomew LK, Greisinger AJ, et al. Behind closed doors: physician-patient discussions about colorectal cancer screening. J Gen Intern Med 2009;24:1228-35.

15. Walsh JM, Karliner L, Burke N, Somkin CP, Pham LA, Pasick R. Physicians' approaches to recommending colorectal cancer screening: a qualitative study. J Cancer Educ 2010;25:385-90.

16. Wackerbarth SB, Tarasenko YN, Joyce JM, Haist SA. Physician colorectal cancer screening recommendations: an examination based on informed decision making. Patient Educ Couns 2007;66:43-50.

17. Guerra CE, Schwartz JS, Armstrong K, Brown JS, Halbert CH, Shea JA. Barriers of and facilitators to physician recommendation of colorectal cancer screening. J Gen Intern Med 2007;22:1681-8.

18. Feeley TH, Cooper J, Foels T, Mahoney MC. Efficacy expectations for colorectal cancer screening in primary care: identifying barriers and facilitators for patients and clinicians. Health Commun 2009;24: 304-15.

19. Lafata JE, Cooper GS, Divine G, et al. Patientphysician colorectal cancer screening discussions: 
delivery of the 5 A's in practice. Am J Prev Med 2011;41:480-6.

20. Ling BS, Trauth JM, Fine MJ, et al. Informed decision-making and colorectal cancer screening: is it occurring in primary care? Med Care 2008;46: S23-9.

21. Fenton JJ, Jerant AF, von Friederichs-Fitzwater MM, Tancredi DJ, Franks P. Physician counseling for colorectal cancer screening: impact on patient attitudes, beliefs, and behavior. J Am Board Fam Med 2011;24:673-81.

22. Morgan DL. Practical strategies for combining qualitative and quantitative methods: applications to health research. Qual Health Res 1998;8:362-76.

23. Kuzel AJ. Sampling in qualitative inquiry. In: Crabtree BF, Miller WL (eds). Doing Qualitative Research. Thousand Oaks, CA: Sage; 1999:33-45.

24. Miles MB, Huberman AM. Qualitative data analysis: an expanded sourcebook. 2nd ed. Thousand Oaks, CA: Sage; 1994.

25. Ajzen I. The theory of planned behavior. Organ Behav Hum Decis Process 1991;50:179-211.

26. Montaño DE, Phillips WR, Kasprzyk D. Explaining physician rates of providing flexible sigmoidoscopy. Cancer Epidemiol Biomarkers Prev 2000;9:665-9.

27. Gennarelli M, Jandorf L, Cromwell C, Valdimarsdottir H, Redd W, Itzkowitz S. Barriers to colorectal cancer screening: inadequate knowledge by physicians. Mt Sinai J Med 2005;72:36-44.

28. Schroy PC 3rd, Geller AC, Crosier Wood M, et al. Utilization of colorectal cancer screening tests: a 1997 survey of Massachusetts internists. Prev Med 2001;33:381-91.

29. Taylor ML, Anderson R. Colorectal cancer screening: physician attitudes and practices. WMJ 2002; 101:39-43.

30. Dulai GS, Farmer MM, Ganz PA, et al. Primary care provider perceptions of barriers to and facilitators of colorectal cancer screening in a managed care setting. Cancer 2004;100:1843-52.

31. Fox SA, Heritage J, Stockdale SE, Asch SM, Duan N, Reise SP. Cancer screening adherence: does physician-patient communication matter? Patient Educ Couns 2009;75:178-84.

32. Banks SM, Salovey P, Greener S, et al. The effects of message framing on mammography utilization. Health Psychol 1995;14:178-84.

33. Abood DA, Black DR, Coster DC. Loss-framed minimal intervention increases mammography use. Womens Health Issues 2005;15:258-64.

34. Ferrer RA, Klein WM, Zajac LE, Land SR, Ling BS. An affective booster moderates the effect of gainand loss-framed messages on behavioral intentions for colorectal cancer screening. J Behav Med 2011; 35:452-61.

35. Zapka JM, Klabunde CN, Arora NK, Yuan G, Smith JL, Kobrin SC. Physicians' colorectal cancer screening discussion and recommendation patterns. Cancer Epidemiol Biomarkers Prev 2011;20:509-21.

36. Deci EL, Ryan RM. Intrinsic motivation and selfdetermination in human behavior. New York: Plenum Press; 1985.

37. Langer EJ, Rodin J. The effects of choice and enhanced personal responsibility for the aged: a field experiment in an institutional setting. J Pers Soc Psychol 1976;34:191-8.

38. Woolf SH. The best screening test for colorectal cancer-a personal choice. N Engl J Med 2000;343: 1641-3.

39. Carpiano RM, Flocke SA, Frank SH, Stange KC. Tools, teamwork, and tenacity: an examination of family practice office system influences on preventive service delivery. Prev Med 2003;36:131-40.

40. Stone EG, Morton SC, Hulscher ME, et al. Interventions that increase use of adult immunization and cancer screening services: a meta-analysis. Ann Intern Med 2002;136:641-51.

41. Garg AX, Adhikari NK, McDonald H, et al. Effects of computerized clinical decision support systems on practitioner performance and patient outcomes: a systematic review. JAMA 2005;293:1223-38.

42. Yabroff KR, Zapka J, Klabunde CN, et al. Systems strategies to support cancer screening in U.S. primary care practice. Cancer Epidemiol Biomarkers Prev 2011;20:2471-9.

43. Montaño DE, Phillips WR. Cancer screening by primary care physicians: a comparison of rates obtained from physician self-report, patient survey, and chart audit. Am J Public Health 1995;85:795-800.

44. Gorin SS, Ashford AR, Lantigua R, et al. Intraurban influences on physician colorectal cancer screening practices. J Natl Med Assoc 2007;99:1371-80. 